\title{
Clinical Applications of Photobiomodulation Therapy in the Management of Breast Cancer-related Lymphedema
}

Junwon Min

Yoonjoon Park

Department of General Surgery, Dankook University College of Medicine, Cheonan, Korea

Received July 1, 2021

Accepted September 8, 2021

\footnotetext{
Correspondence

Junwon Min

Department of General Surgery, Dankook University College of Medicine, 119 Dandae-ro, Dongnam-gu, Cheonan 31116, Korea

Tel.: +82-41-550-3927

Fax: $+82-41-556-3878$

E-mail: junwon77anaver.com

(C) Korean Society for Laser Medicine and Surgery

(c) This is an open access article distributed under the terms of the Creative Commons Attribution NonCommercial License (http://creativecommons.org/ licenses/by-nc/4.0) which permits unrestricted noncommercial use, distribution, and reproduction in any medium, provided the original work is properly cited.
}

Breast cancer-related lymphedema (BCRL) is characterized by the persistent accumulation of interstitial fluid in the peripheral tissues after treatment for breast cancer. Photobiomodulation (PBM) therapy is widely used as supportive care for patients with BCRL. A search was performed in the PubMed database to find relevant articles published over the last 20 years. Randomized controlled trials that evaluated the efficacy of PBM therapy on BCRL were included. A total of 24 studies were identified through the PubMed database. Seven studies were used for the final analysis, after excluding items that did not meet the duplication and inclusion criteria. Although PBM showed some improvement in reducing arm circumference and the symptoms related to BCRL, the results of the meta-analysis did not show any significant benefit in alleviating lymphedema. Further studies are needed with the recruitment of more participants to evaluate the long-term efficacy and safety of PBM in the management of BCRL.

\section{Key words}

Breast cancer; Lymphedema; Photobiomodulation 


\section{INTRODUCTION}

Breast cancer is the most common cancer and the second leading cause of cancer-related deaths for females in the world. ${ }^{1}$ With the increase in the survival rate for breast cancer, the importance of postoperative quality of life has increased. ${ }^{2}$ Breast cancer-related lymphedema (BCRL) is a common and serious complication after breast cancer surgery and it results in adverse outcomes in patients, including pain and limited physical function, and negatively affects their quality of life. ${ }^{3-5}$ Lymphedema is caused by interruption of the lymphatic drainage system resulting in local accumulation of excess lymphatic fluid in the upper arm. ${ }^{4,5}$ Axillary lymph node dissection and adjuvant therapy like radiation and chemotherapy contribute most heavily to risk. ${ }^{6}$ A recent meta-analysis reported that the average incidence of arm lymphedema after breast cancer treatment is about $20 \%$ in breast cancer survivors. ${ }^{7}$

The optimal treatment for lymphedema is not yet clear. The current standard of care is complex decongestion therapy (CDT), which includes manual lymphatic drainage (MLD), bandaging, skin care, exercise, and the use of compression sleeves. ${ }^{8}$ The efficacy of CDT varies widely according to different studies. The combination of MLD with compression bandages has been reported to be probably the most effective method, with excess vol- ume reductions of up to $38 \%$, based on two randomized controlled trials. ${ }^{9,10}$ However, there are limits to these maneuvers. ${ }^{11}$ MLD requires regular and frequent intense physical therapy, and the results will depend greatly on the level of experience of the physical therapist. Also, if lymphedema recurs, treatment should be repeated. There is a clear need to develop new, effective and convenient therapeutic interventions to better manage symptoms and psychosocial factors in BCRL patients.

Recently, low-level laser therapy (LLLT), also known as photobiomodulation (PBM) therapy, has been introduced as a potentially useful non-pharmacological treatment modality for BCRL. PBM therapy, approved by the US Food and Drug Administration (FDA) as a therapeutic intervention, is a non-invasive form of phototherapy. It utilizes light wavelengths (range from 650 to $1000 \mathrm{~nm}$ ) to deliver low irradiance to the target tissue for biological process modulation. ${ }^{12} \mathrm{PBM}$ has been shown to be a safe technique. Several experimental studies have found that PBM therapy is effective in reducing inflammation, promoting lymph vessel regeneration, improving lymphatic motility, alleviate pain, and preventing tissue fibrosis. ${ }^{13,14}$ Previous clinical studies have shown promising effects of LLLT (PBM), when used in addition to conventional therapeutic interventions, for the management of BCRL. The aim of the present review was to evaluate the available

Table 1. Characteristics of included studies

\begin{tabular}{|c|c|c|c|c|c|}
\hline Study & Number of subjects & Treatment design & Control group & Follow up & Evaluation outcomes \\
\hline $\begin{array}{l}\text { Baxter et al. } \\
\qquad(2018)^{16}\end{array}$ & $\mathrm{PBM}=8$, control $=8$ & $\begin{array}{l}2 \text { times per week for } \\
6 \text { weeks + BCRL } \\
\text { conventional therapy }\end{array}$ & $\begin{array}{l}\text { BCRL } \\
\text { conventional therapy }\end{array}$ & 6 weeks, 12 weeks & $\begin{array}{l}\text { Limb circumference, perceived } \\
\text { symptoms, psychological } \\
\text { impacts, activity disability }\end{array}$ \\
\hline $\begin{array}{l}\text { Kilmartin et } \\
\text { al. }(2020)^{17}\end{array}$ & $\mathrm{PBM}=11$, control $=11$ & $\begin{array}{l}2 \text { Times per week for } \\
8 \text { weeks + CDT }\end{array}$ & Inactive PBM + CDT & $\begin{array}{l}3 \text { months, } 6 \text { months, } \\
12 \text { months }\end{array}$ & $\begin{array}{l}\text { Lymphedema symptoms, } \\
\text { symptom distress, limb volume, } \\
\text { adherence rates }\end{array}$ \\
\hline $\begin{array}{l}\text { Ridner et al. } \\
\qquad(2013)^{2}\end{array}$ & $\begin{array}{l}\mathrm{PBM}=15, \mathrm{PBM}+ \\
\mathrm{MLD}=15 \\
\text { control }=16\end{array}$ & $\begin{array}{l}20 \text { min of PBM, } \\
20 \text { min of MLD }\end{array}$ & Compression bandaging & $\begin{array}{l}\text { Post-treatment } \\
\text { immediately } \\
\text { (final treatment) }\end{array}$ & $\begin{array}{l}\text { Extracellular fluid and arm volume, } \\
\text { physical and } \\
\text { psychological symptoms and } \\
\text { skin condition, } \mathrm{OOL}\end{array}$ \\
\hline $\begin{array}{l}\text { Strorz et al. } \\
(2017)^{18}\end{array}$ & $\mathrm{PBM}=20$, control $=20$ & 2 times per week for 4 weeks & Inactive PBM & $\begin{array}{l}4 \text { weeks, } 8 \text { weeks, } \\
12 \text { weeks }\end{array}$ & $\begin{array}{l}\text { Pain, mood state, } 00 \mathrm{~L} \text {, grip } \\
\text { strength, limb volume difference }\end{array}$ \\
\hline $\begin{array}{l}\text { Lau and Che- } \\
\text { ing }(2009)^{19}\end{array}$ & $\mathrm{PBM}=11$, control $=10$ & 3 times per week for 4 weeks & No treatment & 4 weeks & $\begin{array}{l}\text { volumetry, tonometry, DASH ques- } \\
\text { tionnaire symptoms }\end{array}$ \\
\hline $\begin{array}{l}\text { Carati et al. } \\
(2003)^{20}\end{array}$ & $\mathrm{PBM}=33$, control $=33$ & $\begin{array}{l}2 \text { blocks of PBM, } \\
\text { separated by } \\
\text { an } 8 \text { week rest period }\end{array}$ & $\begin{array}{l}1 \text { block of sham therapy, } \\
\text { followed by and } \\
8 \text { week rest period and } \\
\text { then } 1 \text { block of PBM }\end{array}$ & $\begin{array}{l}\text { Post-treatment } \\
1 \text { month, } 2 \text { months }\end{array}$ & $\begin{array}{l}\text { Perimetry, bioimpenance, } \\
\text { tonometry, } \\
\text { shoulder range of movement, } \\
\text { self-reports }\end{array}$ \\
\hline $\begin{array}{l}\text { Ahmed } \\
\text { Omar et } \\
\text { al. }(2011)^{21}\end{array}$ & $\mathrm{PBM}=29$, control $=29$ & $\begin{array}{l}3 \text { times per week for } 12 \\
\text { weeks }\end{array}$ & $\begin{array}{l}\text { Inactive PBM + } \\
\text { exercise, education }\end{array}$ & $\begin{array}{l}4 \text { weeks, } 8 \text { weeks, } \\
12 \text { weeks }\end{array}$ & $\begin{array}{l}\text { Limb circumference, } \\
\text { shoulder morbidity, grip strength }\end{array}$ \\
\hline
\end{tabular}

PBM, photobiomodulation; BCRL, breast cancer-related lymphedema; CDT, complete decongestive therapy; MLD, manual lymphatic drainage; QOL, quality of life; DASH, disabilities of the arm, shoulder and hand. 
literature regarding the effectiveness and safety of PBM therapy for the treatment of BCRL. ${ }^{13-15}$

\section{SUMMARIES OF INDIVIDUAL STUDIES}

A search was performed in the PubMed database without period restriction and limited in the English language. The selected keywords were ("Low-level laser" OR "photobiomodulation" OR "phototherapy") AND ("lymphedema” OR "lymphoedema”) And ("breast cancer"). The author also provided a hand search of the references of the selected studies to identify other possible relevant studies. The articles included should necessarily be presented with full access to the text. We verified those articles that presented titles and summaries that approached the subject of this research, as well as methodology, results, and relevance for tis practical application. In total, 24 studies were identified through the PubMed database. After excluding duplicates and those which did not meet the inclusion criteria, 7 studies were finally included. A summary of included studies is presented in Table 1 and laser treatment parameters are summarized in Table 2.

\section{PBM versus conventional therapy}

Baxter et al. ${ }^{16}$ recruited 17 participants with BCRL and randomized them into the two groups: (1) PBM + BCRL conventional therapy or (2) BCRL conventional therapy alone. Treatment adherence was high in the PBM group (88.9\% of participants completed all treatments). Retention rates were $88.9 \%$ for the BPM group and $100 \%$ for the control group at both 6 and 12 weeks post-randomization. All participants who completed PBM therapy indicated that they were satisfied with the treatment. No serious adverse reactions were reported in this study. In general, the results show a trend toward improvement in symptoms (limb circumference differences, perceived symptoms, and psychological impacts) from baseline to the primary endpoint in both groups. There was a numerically larger improvement in BCRL psychological impacts (except for anxiety) in the PBM group. However, this study did not have the power to investigate effectiveness between groups, and the small sample size along with the variability of the mean values at stated time points may explain these findings.

Kilmartin et al. ${ }^{17}$ evaluated the effectiveness of PBM as a complementary treatment to complete decongestion therapy (CDT) for 12 months after treatment for lymphedema in breast cancer patients. Participants $(n=22)$ were randomly assigned to either an active PBM group or an inactive PBM, control group. Active PBM was administered to participants twice a week at the beginning of each CDT session. Outcome measures included lymphedema symptoms, symptom pain, and limb volume by an infrared perometer. Significantly fewer participants in the active PBM group (55.6\%) compared to the placebo group (83.3\%) reported one or more symptoms of lymphedema ( $p=0.012) 12$ months after the intervention. Significantly, more patients in the active laser group (44.4\%) reported fewer than 2 limb mobility symptoms at 12 months after intervention compared to the placebo group (33.3\%) $(p=$ 0.017). The active PBM group had a statistically significant improvement over time from baseline to 12 months postintervention, from 73 to $11 \%$ of symptom pain of sadness $(p=0.005)$ and from 36 to $0 \%$ of self-perception $(p=0.030)$. Limb volume did not decrease significantly. This trial demonstrated significant benefits of complementary PBM in alleviating symptoms and improving emotional distress in breast cancer patients with lymphedema.

Table 2. Photobiomodulation treatment parameters

\begin{tabular}{|c|c|c|c|c|}
\hline Study & Device type/Model & $\begin{array}{l}\text { Wavelength } \\
\quad(\mathrm{nm})\end{array}$ & $\begin{array}{l}\text { Application duration and } \\
\text { number of sessions }\end{array}$ & Application area(s) \\
\hline Baxter et al. ${ }^{16}$ & $\begin{array}{l}\text { Direct contact; LightForce EX LTS- } \\
1500\end{array}$ & 980 & $1 \mathrm{~min} / \mathrm{spot}$ & $\begin{array}{l}10 \text { points from axilla to wrist on } \\
\text { the affected arm }\end{array}$ \\
\hline Kilmartin et al. ${ }^{17}$ & Direct contact; RianCorp LTU 904H & 904 & $1 \mathrm{~min} / \mathrm{spot}$ & $\begin{array}{l}10 \text { sites in the axilla and a portion of the } \\
\text { chest wall }\end{array}$ \\
\hline Ridner et al. $^{2}$ & Direct contact; RianCorp LTU 904H & 904 & $\begin{array}{l}\text { 20-30s per point, in each treatment grid } \\
\text { ( 20 min total) } 10 \text { sessions (average) }\end{array}$ & $\begin{array}{l}\text { Not specifically stated: "grids for the } \\
\text { areas to be treated were identified" }\end{array}$ \\
\hline Strorz et al. ${ }^{18}$ & Non-contact mode; TIMELAS Vital & 980 & 10 min per session & Axillary \\
\hline Lau and Cheing $^{19}$ & $\begin{array}{l}\text { Scanning } 50 \mathrm{~cm} \text { above skin; } \\
\text { Comby } 3 \text { Terza Serie, Model D }\end{array}$ & $\begin{array}{l}808 \\
905 \times 2\end{array}$ & $20 \min 12$ session & Entire axilla $\left(144 \mathrm{~cm}^{2}\right)$ \\
\hline Carati et al. ${ }^{20}$ & Direct contact; RianCorp LTU 904H & 904 & $1 \mathrm{~min} / \mathrm{spot} ; 17 \mathrm{~min} / \mathrm{session}$ & 17 spots, $2 \mathrm{~cm}$ apart in axilla \\
\hline Ahmed Omar etal. ${ }^{21}$ & Direct contact; RianCorp Ga-As laser & 904 & $2 \mathrm{~min} / \mathrm{spot} ; 20 \mathrm{~min}$ & $\begin{array}{l}3 \text { spots antecubital fossa, } \\
7 \text { spots axilla }\left(0.2 \mathrm{~cm}^{2} / \mathrm{spot}\right)\end{array}$ \\
\hline
\end{tabular}




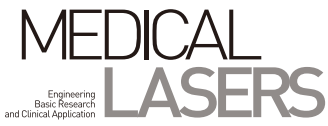

Ridner et al. ${ }^{2}$ randomized controlled trial (RCT) was performed on 46 women with unilateral BCRL, randomized to one of three treatment groups: (1) PBM + compression bandage, (2) MLD + compression bandage, or (3) combined MLD/PBM + Compression bandages. For the PBM group, the median duration of lymphedema was 27 months (IQR: 6, 58). The median, interquartile range, and effect size for each group of limb volume were reported. All three groups showed clinically and statistically significant volume reductions ( $p<0.001)$, but no statistically significant intergroup differences were found (circumference $p=0.422$ ). The largest reported effect size was for the difference in circumference between the two PBM groups. The authors suggest that PBM followed by compression bandage may be effective in reducing volume compared to MLD or composite MLD/PBM, followed by compression bandage. However, since each group received a compression bandage after the procedure, the beneficial effect of the compression bandage itself cannot be ignored. Assessment of upper extremity (UE) pain/ pain was included as part of the Lymphedema Symptom Intensity and Pain Scale-Arm (LSIDS-A). The effect size for UE pain compared to baseline immediately after final treatment was 0.24 for the MLD group, -0.31 for the PBM group, and -0.07 for the MLD + PBM group. No intergroup comparisons for UE pain/pain were performed, however, there were no significant differences between groups for total LSIDS-A scores.

\section{PBM versus sham laser}

Storz et al..$^{18}$ evaluated the effects of PBM therapy on lymphedema-related pain, quality of life, grip strength and limb volume difference with forty patients. After treatment, a 50\% decrease in central pain score and an increase in the average quality of life was observed. Mean grip strength was consistently higher after 8 sessions of PBM therapy compared to pretreatment. However, there were no statistically significant between-group differences ( $p>0.05)$ over time.

In 21 women with BCRL, Lau and Cheing ${ }^{19}$ investigated the effect of PBM in RCT compared to a waitlist control group. In the PBM group ( $n=11)$, a mean decrease of $16 \%$ in arm volume immediately after treatment $184.2 \pm 8.5 \%$, $p<0.00011$ and a mean decrease of $28 \%$ after 4 weeks of treatment $(71.9 \pm 6.3 \%, p<0.0001)$. In the control group, arm volume increased on average by $6 \%$ after 4 weeks of treatment (106.0 $\pm 4.3 \%, p<0.0001)$. Although differences between groups at 4 weeks post-intervention follow-up ( $p=0.044)$ did not reach Bonferroni-corrected statistical significance (set to $<0.017$ ), Lau and Cheing ${ }^{19}$ suggest that
PBM may be useful in conjunction with other treatments and reduce the need for expensive and labor-intensive treatments.

Carati et al. ${ }^{20}$ performed a two-component crossover study. The first was a double-blind, randomized, sham (placebo) controlled crossover trial of 9-session cycles of PBM ( $n=26)$ versus sham PBM treatment $(n=27)$. After 1 cycle of PBM, no significant differences in volume were found and there were no significant differences between groups. The second component of the test is designed to compare one and two cycles of the PBM. After completing the crossover phase, 11 participants in the original sham laser group (unblinded) received a second 9-session cycle of PBM treatment, and data were pooled to increase the number of participants receiving both cycles of active PBM to 37. There was no statistically significant decrease from baseline in mean affected limb volume after 2 cycles of PBM therapy immediately after treatment ( $p=0.442), 1$ month after treatment ( $p=0.119)$, or 3 months after treatment $(p=0.061)$, although volume was decreased. However, compared with the sham group, the 2-cycle PBM group showed a significant decrease in mean limb volume at 3 months after treatment $(89.7 \pm 46 \mathrm{ml}$ decrease vs. $32.1 \pm 3.4 \mathrm{ml}$ increase; $p=0.017$ ). At 2 to 3 months after the second PBM block, $31 \%$ of participants had a clinically significant decrease $(>200 \mathrm{ml})$ in affected limb volume ( $p$ $=0.01 \mathrm{I}$ compared to $4 \%$ in the sham group. Pain was not reported as an independent outcome.

Ahmed Omar et al. ${ }^{21}$ RCT was performed comparing PBM $(n=25)$ and sham laser $(n=25)$. Of the 58 women initially randomized, 8 were lost for follow-up $(4$ women in each group): 1 with cellulitis and 3 with non-adhesion from the PBM group withdrew. In the sham group, 2 patients withdrew with cellulitis and 2 with non-adhesion. The mean duration of lymphedema was 13.98 months ( 2 months). Limb circumference was significantly decreased in the PBM group compared to baseline at each time point $(p<0.05)$. There was a significant within-group decrease $(p<0.05)$ in limb circumference in the sham group, except at week 4. Differences between groups, with a greater reduction in the PBM than in the sham group, were significant at weeks 8, 12, and 16 ( $p<0.01)$. The authors concluded that PBM may be effective in reducing arm circumference in BCRL patients, and the results could last up to 16 weeks.

\section{DISCUSSION}

The laser is an electromagnetic radiation from the light amplification by stimulated emission of radiation gener- 
ated in a resonant optical cavity from an active medium and an excitation source. ${ }^{22}$ The PBM has been used as a resource for physical therapy in different clinical settings. As a relatively novel therapeutic tool for the treatment of BCRL, PBM has gained increasing popularity since its approval by the US FDA in 2007.

The underlying mechanism of using low-levels light for therapeutic tool includes light absorption, targeting and activating cytochrome oxidase in the mitochondrial membrane, leading to greater consumption of cellular oxygen and ultimately increased metabolic energy production, which is used for cellular repair. ${ }^{23}$ Research of the use of this laser at the low-intensity wavelength suggest effects at the cellular level with stimulation of lymphocytes and local fluid circulation, ${ }^{24}$ and stimulation of macrophage cells and the immune system which decrease the risk of infection. ${ }^{25}$

Over the past two decades, several RCTs ${ }^{2,16-22}$ and observational studies ${ }^{26,27}$ have been published in this area. Decreased limb volume in women with BCRL is associated with improved mobility and quality of life. It may also be reasonable to expect that a decrease in swelling in the arm could result in changes in the quality or texture of the skin (such as fibrosis) or concomitant pain severity. Treatments that contribute to a significant reduction in swelling should be considered as viable treatment options in BCRL management. ${ }^{15}$

A reduction in volume change between the affected and unaffected arms was determined in four trials evaluating the outcome of PBM in BCRL patients.17-20 In metaanalysis using three trials, the combined standardized mean difference (SMD) of arm volume was 0.04 (95\% $\mathrm{Cl}:-0.32-0.41)$ after treatment and $-0.53(95 \% \mathrm{Cl}:-1.10$ $-0.04)$ at 1 month after treatment. No significant difference in arm volume was observed between the PBM groups and the control groups after the treatment period.3 Many trials demonstrated that treatment with PBM resulted in reduction of pain felt by women with BCRL. ${ }^{2.16-18}$ However, evidence for PBM-induced pain reduction in $\mathrm{BCRL}$ is not available as no significant differences in pain reduction were observed in the meta-analysis. ${ }^{3}$ This is thought to be the reason why studies used different pain score. And other potential causes of BCRL pain include musculoskeletal disorders, cervical neuropathy, brachial plexopathy, neuropathy le.g., chemotherapy-induced peripheral neuropathyl, post-mastectomy pain syndrome, and bone metastases, which also cannot be ignored. Regarding harm, there were no apparent differences in adverse treatment-related events in PBM versus control groups across studies, but important contraindications and precautions for PBM should be considered when using this modality. In the study, PBM did not increase the risk of cellulitis, however, patients must undergo appropriate medical management when they observe the symptoms and signs of cellulitis. ${ }^{15}$

\section{CONCLUSIONS}

Although the results of meta-analysis did not show significant benefit in relieving lymphedema, PBM demonstrated a slight improvement in reducing arm volume and symptom- related BCRL like pain without any complications. Overall, there were some limitations in the studies, and these must be considered in future studies. In conclusion, further well-designed trials are needed to confirm the long-term efficacy and safety of PBM in BCRL management.

\section{CONFLICT OF INTEREST}

No potential conflict of interest relevant to this article was reported.

\section{FUNDING}

This research was supported by the Research Program funded by the Korea Forestry Promotion Institute (2021396C10-2123-0107).

\section{ORCID}

Junwon Min, https://orcid.org/0000-0001-7440-2561

Yoonjoon Park, https://orcid.org/0000-0002-1912-1422

\section{REFERENCES}

1. Kang SY, Kim YS, Kim Z, Kim HY, Kim HJ, Park S, et al. Breast cancer statistics in Korea in 2017: data from a breast cancer registry. J Breast Cancer 2020;23:115-28.

2. Ridner SH, Poage-Hooper E, Kanar C, Doersam JK, Bond SM, Dietrich MS. A pilot randomized trial evaluating low-level laser therapy as an alternative treatment to manual lymphatic drainage for breast cancer-related lymphedema. Oncol Nurs Forum 2013;40:383-93.

3. Chen HY, Tsai HH, Tam KW, Huang TW. Effects of photobiomodualtion therapy on breast cancer-related lymphoedema: a systematic review and meta-analysis of randomised controlled trials. Complement Ther Med 2019;47:102200.

4. Ahmed RL, Prizment A, Lazovich D, Schmitz KH, Folsom AR. Lymphedema and quality of life in breast cancer survivors: the 
lowa Women's Health Study. J Clin Oncol 2008;26:5689-96.

5. McLaughlin SA, Wright MJ, Morris KT, Sampson MR, Brockway JP, Hurley KE, et al. Prevalence of lymphedema in women with breast cancer 5 years after sentinel lymph node biopsy or axillary dissection: patient perceptions and precautionary behaviors. J Clin Oncol 2008;26:5220-6.

6. Bao T, Iris Zhi W, Vertosick EA, Li QS, DeRito J, Vickers A, et al. Acupuncture for breast cancer-related lymphedema: a randomized controlled trial. Breast Cancer Res Treat 2018;170:7787.

7. DiSipio T, Rye S, Newman B, Hayes S. Incidence of unilateral arm lymphoedema after breast cancer: a systematic review and meta-analysis. Lancet Oncol 2013;14:500-15.

8. Runowicz CD, Leach CR, Henry NL, Henry KS, Mackey HT, Cowens-Alvarado RL, et al. American Cancer Society/American Society of Clinical Oncology Breast Cancer Survivorship Care Guideline. J Clin Oncol 2016;34:611-35.

9. Johansson K, Albertsson M, Ingvar C, Ekdahl C. Effects of compression bandaging with or without manual lymph drainage treatment in patients with postoperative arm lymphedema. Lymphology 1999;32:103-10.

10. McNeely ML, Magee DJ, Lees AW, Bagnall KM, Haykowsky M, Hanson J. The addition of manual lymph drainage to compression therapy for breast cancer related lymphedema: a randomized controlled trial. Breast Cancer Res Treat 2004;86:95-106.

11. Javid SH, Anderson BO. Mounting evidence against complex decongestive therapy as a first-line treatment for early lymphedema. J Clin Oncol 2013;31:3737-8.

12. Khan I, Arany P. Biophysical approaches for oral wound healing: emphasis on photobiomodulation. Adv Wound Care (New Rochellel 2015;4:724-37.

13. E Lima MT, E Lima JG, de Andrade MF, Bergmann A. Low-level laser therapy in secondary lymphedema after breast cancer: systematic review. Lasers Med Sci 2014;29:1289-95.

14. Omar MT, Shaheen AA, Zafar H. A systematic review of the effect of low-level laser therapy in the management of breast cancer-related lymphedema. Support Care Cancer 2012;20:2977-84.

15. Smoot B, Chiavola-Larson L, Lee J, Manibusan H, Allen DD. Effect of low-level laser therapy on pain and swelling in women with breast cancer-related lymphedema: a systematic review and meta-analysis. J Cancer Surviv 2015;9:287-304.

16. Baxter GD, Liu L, Tumilty S, Petrich S, Chapple C, Anders JJ; Laser Lymphedema Trial Team. Low level laser therapy for the management of breast cancer-related lymphedema: a randomized controlled feasibility study. Lasers Surg Med 2018;50:924-32.
17. Kilmartin L, Denham T, Fu MR, Yu G, Kuo TT, Axelrod D, et al. Complementary low-level laser therapy for breast cancer-related lymphedema: a pilot, double-blind, randomized, placebocontrolled study. Lasers Med Sci 2020;35:95-105.

18. Storz MA, Gronwald B, Gottschling S, Schöpe J, Mavrova R, Baum S. Photobiomodulation therapy in breast cancer-related lymphedema: a randomized placebo-controlled trial. Photodermatol Photoimmunol Photomed 2017;33:32-40.

19. Lau RW, Cheing GL. Managing postmastectomy lymphedema with low-level laser therapy. Photomed Laser Surg 2009;27:763-9.

20. Carati CJ, Anderson SN, Gannon BJ, Piller NB. Treatment of postmastectomy lymphedema with low-level laser therapy: a double blind, placebo-controlled trial. Cancer 2003;98:1114-22.

21. Ahmed Omar MT, Abd-El-Gayed Ebid A, El Morsy AM. Treatment of post-mastectomy lymphedema with laser therapy: double blind placebo control randomized study. J Surg Res 2011;165:82-90.

22. Dompe C, Moncrieff L, Matys J, Grzech-Leśniak K, Kocherova I, Bryja $A$, et al. Photobiomodulation-underlying mechanism and clinical applications. J Clin Med 2020;9:1724.

23. Wang X, Tian F, Reddy DD, Nalawade SS, Barrett DW, Gonzalez-Lima F, et al. Up-regulation of cerebral cytochromec-oxidase and hemodynamics by transcranial infrared laser stimulation: a broadband near-infrared spectroscopy study. J Cereb Blood Flow Metab 2017;37:3789-802.

24. Liebert AD, Bicknell BT, Adams RD. Protein conformational modulation by photons: a mechanism for laser treatment effects. Med Hypotheses 2014;82:275-81.

25. Jang DH, Song DH, Chang EJ, Jeon JY. Anti-inflammatory and lymphangiogenetic effects of low-level laser therapy on lymphedema in an experimental mouse tail model. Lasers Med Sci 2016;31:289-96.

26. Dirican A, Andacoglu O, Johnson R, McGuire K, Mager L, Soran A. The short-term effects of low-level laser therapy in the management of breast-cancer-related lymphedema. Support Care Cancer 2011;19:685-90.

27. Piller NB, Thelander A. Treatment of chronic postmastectomy lymphedema with low level laser therapy: a 2.5 year follow-up. Lymphology 1998;31:74-86.

How to cite this article: Min J, Park Y. Clinical applications of photobiomodulation therapy in the management of breast cancer-related lymphedema. Med Lasers 2021;10:189-194. https://doi.org/10.25289/ML.2021.10.4.189 